\title{
Glaucoma Awareness and Knowledge among Jordanian People
}

\author{
Khalid Al-Zubi ${ }^{1}$, Fawaz Sarayrah ${ }^{1} \&$ Mahmoud Al-Awaishah ${ }^{1}$ \\ ${ }^{1}$ Faculty of Medicine, Mutah University, Al-Karak, Jordan \\ Correspondence: Khalid Al-Zubi, Faculty of Medicine, Mutah University, Al-Karak, Jordan.
}

Received: March 29, 2017 Accepted: May 1, 2017 Online Published: May 8, 2017

doi:10.5539/gjhs.v9n8p40 URL: https://doi.org/10.5539/gjhs.v9n8p40

\begin{abstract}
Glaucoma, a preventable condition, is the second leading reason behind blindness globally. The asymptomatic type of glaucoma is the most prevalent type, which explains the late presentation and diagnosis. The objective of the study has been developed to assess the levels of awareness about glaucoma among Jordanian people. This is a national study comprising of 511 subjects, aged 20 years and above. The participants were asked to fill the survey forms after signing the consent to the study. The results of the study revealed that 147 individuals $(28.77 \%)$ were completely unaware of glaucoma, and 249 individuals (48.73\%) had low level of knowledge about glaucoma. $77.5 \%$ of the subjects were either unaware or partial level of knowledge about the condition; however, they displayed an acceptable level of awareness. The outcomes among Jordanian people explained the delayed diagnosis of this blinding disease in the country. There is a need of proper educational strategies to educate Jordanian people about glaucoma.
\end{abstract}

Keywords: awareness, disease, glaucoma, Jordan, knowledge

\section{Introduction}

The main leading causes of blindness are particularly the eye diseases, associated with aging that may include conditions like glaucoma, cataract, macular degeneration, and diabetic retinopathy (Rhee et al., 2013). Glaucoma is recognized as a group of eye pathologies that affect the optic nerve, causing irreversible loss of vision. According to the World Health Organization (WHO), glaucoma is identified around the globe as the second leading cause of blindness (World Health Organization, 2016). The prevalence of glaucoma is 67 million among whom 6.6 million people subsequently turn blind annually (Sathyamangalam et al., 2009; Tielsch et al., 1991). Therefore, the condition is regarded as a major socioeconomic problem faced by most of the countries. One of the risk factors for subsequent blindness is the late diagnosis of glaucoma, which is positively associated with unawareness and the poor knowledge about the disease (Sathyamangalam et al., 2009; Saw et al., 2003; Tielsch et al., 1991). On the basis of nerve damage, different types of glaucoma are considered to be a type of optic neuropathy.

Glaucoma has been categorized into two primary types including open angle glaucoma and closed angle glaucoma (Young et al., 2015). High intraocular pressure has been identified as the key factor causing the optic nerve damage. Yet, the condition can still be diagnosed in the eyes that may present with normal or even lower than normal ocular pressure. Unfortunately, there has been no progress in identifying a definite treatment for glaucoma till now. The symptoms of the disease can be controlled and blindness can be prevented through early diagnosis and treatment. Asymptomatic glaucoma, clinically recognized as the open-angle glaucoma, is the commonly occurring type of the condition. The vision disturbance initially affects either the peripheral vision or the side vision; however, patients usually fail to identify the symptoms until significant damage is attained in the form of blindness (Rewri \& Kakkar, 2014). Therefore, regular eye examinations are needed for a proper and early diagnosis of disease condition to prevent irreversible damage to optic nerve.

\subsection{Problem Statement}

Studies conducted among the Jordanian population have revealed that the cases of blindness, presenting in the ophthalmological clinics, display glaucoma condition as a highly prevalent (Rabiu et al., 2014; Hamarneh, 2013). The study has presumed that the higher incidence is occurring due to the lack of awareness as well as inefficient screening for the glaucoma. Moreover, late diagnosis may also increase the risk of glaucoma associated visual disability. Therefore, the study has been implemented to evaluate the Jordanian population for their knowledge and awareness regarding the condition of glaucoma. 


\subsection{Significance of the Study}

The awareness and knowledge about glaucoma greatly influence the treatment-seeking behavior of individuals. The late presentation of glaucoma and its symptoms is due to the lack of awareness about the disease, which significantly increases the risk of blindness. It is recognized that if the individuals have enough knowledge about the asymptomatic course and predictors of glaucoma, it is possible that the patients will seek for screening and clinical assistance. Therefore, this study has mainly focused on the awareness regarding glaucoma among Jordanian population.

\subsection{Aim of the Study}

Proper level of knowledge about glaucoma can lead to early diagnosis and better management of the disease. The study aims to measure the level of glaucoma awareness and knowledge among the Jordanian people.

\section{Literature Review}

After cataract, glaucoma has been known as the second leading cause of blindness. The major risk element for the development of glaucoma has been identified as the increased ocular pressure. The ocular pressure functions to produce aqueous humor by ciliary processes in the eye and also drains the fluid through trabecular meshwork (Hudda, 2016). The obstruction and degeneration of trabecular meshwork reduce the flow of aqueous humor through trabecular meshwork resulting in open-angle glaucoma. On the other hand, forward displacement of final roll and root of iris against cornea causes close-angle glaucoma due to inability of aqueous humor to flow through trabecular meshwork.

Previous studies regarding glaucoma awareness and knowledge have shown low levels of knowledge among people about the blindness (Rewri \& Kakkar, 2014; Rhee et al., 2013; Komolafe et al., 2013). A study recruited 704 subjects from a tertiary care hospital in South India, which revealed that only $34(4.8 \%)$ participants were aware about glaucoma; whereas, 22 (3.1\%) participants had limited knowledge (Prabhu et al., 2013). Another study revealed that, awareness has been indicated by around $13.5 \%$ of the study population, and some knowledge was expressed by $8.7 \%$ of them (Sathyamangalam et al., 2009). Whereas, a study conducted among the patients in Abuja revealed that $74.5 \%$ of the individuals were familiar with the condition of glaucoma; however, only $14.5 \%$ managed to state some knowledge about the disease (Monareng \& Onunkwor, 2012). 32.5\% of the individuals recognized glaucoma as a blinding disease; although worldwide, it has been known as the main cause of blindness (Katibeh et al., 2014). As compared to other optic diseases; such as cataract and diabetic retinopathy, the participants had significantly decreased the level of knowledge about glaucoma (Katibeh et al., 2014). On the contrary, $74 \%$ of the participants from Philadelphia believed that glaucoma was one of the causes of blindness (Altangerel et al., 2009).

An investigation has pronounced that the rural population is inclined to have poor awareness, concerning the vision problems like glaucoma (Krishnaiah et al., 2005). It turned out that only $2.4 \%$ of participants were aware of glaucoma among the people, who attended the ophthalmic outreach services in the region of South Western Ethiopia (Tenkir et al., 2010). Likewise, $60.6 \%$ individuals presenting in a hospital of Eastern Nepal were found to be aware of the term glaucoma; though only $5.5 \%$ of the total participants had some knowledge (Gyawali \& Sarkar, 2014). Moreover, only few participants $(4 \%)$ in a study conducted in Toronto correctly reported that glaucoma affects peripheral vision (Jin et al., 2014).

The education level, family history, and gender were significantly correlated with the extent of knowledge that individuals possessed. The family history of glaucoma plays a significant role in creating awareness about the disease. The higher education level was significantly associated with better knowledge and awareness about glaucoma (Nkum et al., 2015). Another study revealed that increasing age, lower socio-economic status, and lack of education can be the major factors that may precede to low awareness regarding glaucoma (Islam et al., 2015). It has been stated yet again in another study that $21.1 \%$ of the participants were aware about glaucoma; whereas, only $6.3 \%$ had good knowledge about this disease (Ogbonnaya et al., 2016). Moreover, only few individuals (0.7\%) were aware that glaucoma is an asymptomatic disease. A study conducted among the people of Bangladesh revealed that approximately $50 \%$ of the population were concerned about glaucoma; whereas, $35 \%$ had proper knowledge about this disease (Hudda, 2016).

\section{Materials and Methods}

A sample of 511 individuals aged 20 years old or above, were asked to answer the structured questionnaire, designed by the researchers and ophthalmologists to assess their awareness and knowledge about glaucoma. The population has been recruited randomly from different institutions from the month of June, 2014 to May, 2015. The individuals, who consented for the evaluation, were briefed about the purpose of the study, and were provided with 
a written consent to sign. The evaluation form has been translated to Arabic for better understanding of the participants (Annexure 1). Ethical approval for the study has been provided by the Scientific Committee of Faculty of Medicine.

Subjects, who had heard of glaucoma, were considered as aware about the disease, and their knowledge was assessed on the basis of their understanding regarding the disease. The levels of knowledge were studied in correlation between the demographics and disease factors. The responses of the subjects' awareness about glaucoma were analyzed to assess their level of knowledge about the disease. The procedure was carried out by ophthalmologists, who divided the knowledge into four grades: low, average, good, and excellent. These grades were defined by the exact number of correctly answered questions related to the risk factors, treatment options, and glaucoma definition. The details on the knowledge about glaucoma were analyzed only for subjects, who were aware about glaucoma. The data was analysed through Statistical Package of Social Sciences (SPSS), and P-value less than the level of significance $(\alpha=0.05)$ was considered statistically significant.

\section{Results}

The study included 511 subjects, aged 20 years or more; out of them 235 (46\%) were males and 276 (54\%) were females. Regarding the education level of the participants, 144 (28.2\%) subjects had high school or below level of education; whereas, the others had higher levels of education (Table 1).

Table 1. Educational Levels for the Participants

\begin{tabular}{lll}
\hline Qualification & Number of Participants & Valid Percentage \\
\hline High School - Below & 144 & 28.2 \\
Diploma & 246 & 48.2 \\
Bachelor & 93 & 18.2 \\
High Education(Master Degree or PhD) & 28 & 5.4 \\
Total & 511 & $100 \%$ \\
\hline
\end{tabular}

Majority of the participants were from Amman, Karak, and Zarqa which are one of the major cities of Jordan. It has been estimated that Amman accommodates about 3 million people of Jordan; while 1 million individuals lives in Zarqa; and about half a million resides in the Southern region that includes the city of Karak. The evaluation in these big cities aided in involving major representatives of the country from Southern districts along with Zarqa that also may facilitate the people from the Eastern regions (Moussa et al., 2014). The geographical distribution of the participants has been shown in Figure 1 .

\section{Geographic Distribution}

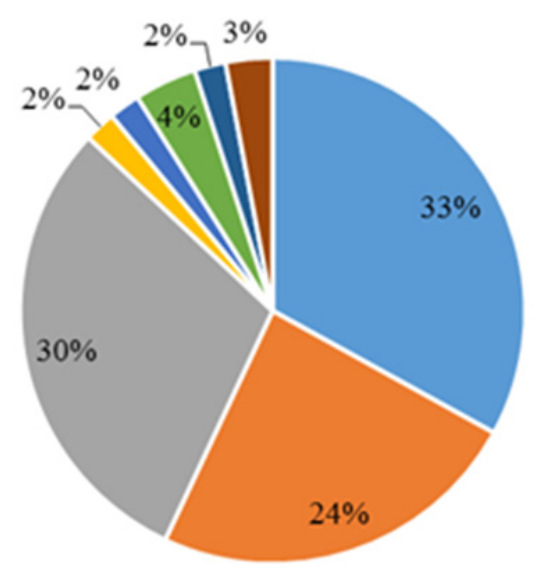

= Amman = Zarqa " Karak " Jerash = Ailoun "Salt = Irbid "Aqaba

Figure 1. Geographic Distribution of Participants $(\mathrm{N}=511)$ 
Out of the 511 subjects, 364 (71.2\%) subjects were aware of glaucoma, and 147 (28.8\%) subjects were unaware about glaucoma. The responses of the subjects, aware about glaucoma, were analyzed to assess their level of knowledge about the disease. 249 (48.73\%) subjects had low level of knowledge about the disease; 78 (15.26\%) subjects had average level; 30 (5.87\%) subjects had good level; and 7 (1.37\%) subjects had excellent level of knowledge (Table 2).

Table 2. Awareness and Knowledge Levels of the Participants about Glaucoma

\begin{tabular}{lll}
\hline Awareness Level & Number of Participants & Percentage of participants \\
\hline Unaware & 147 & $28.77 \%$ \\
Low level & 249 & $48.73 \%$ \\
Average level & 78 & $15.26 \%$ \\
Good level & 30 & $5.87 \%$ \\
Excellent level & 7 & $1.37 \%$ \\
Total & 511 & $100 \%$ \\
\hline
\end{tabular}

It has been identified that $28.77 \%$ of the participants were unaware about glaucoma, and $48.73 \%$ of them had lower level of knowledge about it. Thus, it can be said that majority (77.5\%) of the participants were either unaware of glaucoma or had low level of knowledge about the disease (Table 2). No significant correspondence was observed between the level of awareness and knowledge about glaucoma and the age, gender, education, and work of the subject.

\section{Discussion}

Glaucoma is a blinding disease that affects a huge number of people all over the world. The most common type of glaucoma is asymptomatic, which explains late presentation and diagnosis of this disease. Almost one third of glaucoma patients had become blind due to late diagnosis (Galloway et al., 2016; Chrlson et al., 2015; Malihi et al., 2014). Early diagnosis and treatment of glaucoma are the significant factors in reducing the percentage of blind patients due to this disease. Previous studies across the world have shown the potential cost savings, associated with proper preventive eye care (Javitt, 1995). Although, the incidence of glaucoma is expected to increase with increasing age (Saw et al., 2003).

Awareness means that the subject has heard about the disease, but does not know about the pathogenesis, presentation, risk factors, and treatment (Sathyamangalam et al., 2009). Proper knowledge about the disease nature may lead to proper medical attention. The diagnosis of glaucoma is usually made at advanced stage, when there is already significant loss of vision. If individuals are well aware about the presentation and risk factors of glaucoma, there will be decreased occurrence of blindness preceding to this condition.

In present study, 364 (71.2\%) subjects claimed that they had heard about glaucoma, but only 7 (1.37\%) subjects were found to have excellent knowledge about it. Despite the acceptable degree of knowledge concerning the glaucoma, majority of the people still had poor knowledge about this blinding disease. Higher extent of awareness and quality of knowledge about glaucoma were observed among the developed countries as compared to developing countries (Komolafe et al., 2013).

The awareness of glaucoma among the people from rural regions was investigated to be very low $(0.32 \%)$. Moreover, the respondents, who had awareness regarding glaucoma, were not known to the information whether the visual loss was reversible or permanent (Krishnaiah et al., 2005). The morbidity related to this disease is reduced by early diagnosis and treatment. Thus, urgent need for proper health education strategy is needed to increase awareness and knowledge among the people about glaucoma. This might change the behaviour of people to seek early and regular eye care (Sathyamangalam et al., 2009).

A population based survey found that only $46.6 \%$ of the individuals were aware about glaucoma; whereas, $19.2 \%$ were able to define the causes and risk factors of the disease. Moreover, $32.5 \%$ of the participants stated glaucoma as the major cause of vision loss (Katibeh et al., 2014). Another study stated that around $76 \%$ of the study respondents were unaware about the terminology of glaucoma (Mansouri et al., 2006). Moreover, a study conducted in Nigeria revealed that only about $21.1 \%$ of the participants were aware about glaucoma. It also indicated that the positive indication in family history, education, and gender may also be significantly related to 
the awareness regarding glaucoma (Ogbonnaya et al., 2016).

\section{Conclusion}

The outcomes of the study have presented the facts about degree of knowledge and awareness about glaucoma among the Jordanian population. Awareness about glaucoma helps in early diagnosis of the disease and prevent glaucoma associated blindness. Despite the acceptable level of awareness, there is definitely a low level of knowledge about glaucoma among Jordanian people, which may explain late presentation and diagnosis of glaucoma in the country. There is a need to establish a proper system to increase people's awareness and mainly knowledge about glaucoma through efficient information, education, and communication strategies. The media can play a great role in increasing the awareness and knowledge levels about chronic diseases like glaucoma. Moreover, schools and universities can also play a major role in this strategy through medical educational lectures or meetings. The Jordan Medical Association and the Jordanian Ophthalmic Society can also participate in this process through regular educational meetings with local communities.

\section{Acknowledgements}

The authors are very thankful to all the associated personnel in any reference that contributed in/for the purpose of this research. Further, this research holds no conflict of interest and is not funded through any source.

\section{Competing Interests Statement}

The authors declare that they has no competing or potential conflicts of interest.

\section{References}

Altangerel, U., Nallamshetty, H. S., Uhler, T., Fontanarosa, J., Steinmann, W.C., Almodin, J. M., Chen, B. H., \& Henderer, J. D. (2009). Knowledge about glaucoma and barriers to follow-up care in a community glaucoma screening program. Canadian Journal of Ophthalmology/Journal Canadien d'Ophtalmologie, 44(1), 66-69. https://doi.org/10.3129/i08-175

Charlson, E. S., Sankar, P. S., Miller-Ellis, E., Regina, M., Fertig, R., Salinas, J., ... \& Chua, M. (2015). The primary open-angle African American glaucoma genetics study: baseline demographics. Ophthalmology, 122(4), 711-720. https://doi.org/10.1016/j.ophtha.2014.11.015

Galloway, N. R., Amoaku, W. M., Galloway, P. H., \& Browning, A. C. (2016). The Ageing Eye. In Common Eye Diseases and their Management (pp. 171-184). Springer International Publishing. https://doi.org/10.1007/978-3-319-32869-0_19

Gyawali, R., \& Sarkar, N. (2014). Glaucoma awareness in a hospital presenting population in Eastern Nepal. Journal of Glaucoma, 23, 594-598. https://doi.org/10.1097/IJG.0b013e31828700de

Hamarneh, S. (2013). Causes of blindness in the Jordanian population. Middle East Journal of Internal Medicine, 6(2). https://doi.org/10.5742/MEJIM.2013.62221

Hudda, S. M. (2016). A Survey Based Study on Awareness of Eye Diseases among the population of Bangladesh (Doctoral dissertation, East West University).

Islam, F. M., Chakrabarti, R., Islam, S. Z., Finger, R. P., \& Critchley, C. (2015). Factors associated with awareness, attitudes and practices regarding common eye diseases in the general population in a rural district in Bangladesh: The Bangladesh Population-based Diabetes and Eye Study (BPDES). PloS one, 10(7), e0133043. https://doi.org/10.1371/journal.pone.0133043

Javitt, J. C. (1995). Preventing blindness in Americans: The need for eye health education. Survey of Ophthalmology, 40, 41-44. https://doi.org/10.1016/S0039-6257(95)80045-X

Jin, Y. P., Miller, G., Lin, K., \& Trope, G. E. (2014). Glaucoma knowledge in a black community in Toronto. International Journal of Ophthalmology \& Eye Science, 2, 59-64. https://doi.org/10.19070/2332-290X-1400011

Katibeh, M., Ziaei, H., Panah, E., Moein, H.R., Hosseini, S, Kalantarion, M., Eskandari, A., \& Yaseri, M. (2014). Knowledge and awareness of age related eye diseases: A population-based survey. Journal of ophthalmic \& vision research, 9(2), 223-31.

Komolafe, O. O., Omolase, C. O., Bekibele, C. O., Ogunley, O. A., Komolafe, O. A., \& Omotayo, F. O. (2013). Awareness and knowledge of glaucoma among workers in a Nigerian tertiary health care institution. Middle East African Journal of Ophthalmology, 20, 163-167. https://doi.org/10.4103/0974-9233.110609

Krishnaiah. S., Kovai, V., Srinivas, M., Shamanna, B.R., Rao, G. N., \& Thomas, R. (2005). Awareness of 
glaucoma in the rural population of Southern India. Indian journal of ophthalmology, 53(3), 205. https://doi.org/10.4103/0301-4738.16685

Malihi, M., Moura Filho, E. R., Hodge, D. O., \& Sit, A. J. (2014). Long-term trends in glaucoma-related blindness in Olmsted County, Minnesota. Ophthalmology, 121(1), 134-141. https://doi.org/10.1016/j.ophtha.2013.09.003

Mansouri, K., Orgül, S., Meier-Gibbons, F., \& Mermoud, A. (2006). Awareness about glaucoma and related eye health attitudes in Switzerland: a survey of the general public. Ophthalmologica, 220(2), 101-108. https://doi.org/10.1159/000090574

Monareng, L. V., \& Onunkwor, C. I. (2012). Glaucoma knowledge of patients in Abuja Nigeria. Africa Journal of Nursing and Midwifery, 14, 3-15.

Moussa, A., Reza, M. M., Hamid, S., \& Elaheh, A. (2014). ONLINE SUBMISSION. Eye.

Nkum, G., Lartey, S., Frimpong, C., Micah, F., \& Nkum, B. (2015). Awareness and knowledge of glaucoma among adult patients at the eye clinic of a teaching hospital. Ghana medical journal, 49(3), 195-199. https://doi.org/10.4314/gmj.v49i3.11

Ogbonnaya, C. E., Ogbonnaya, L. U., Okoye, O., \& Kizor-Akaraiwe, N. (2016) Glaucoma Awareness and Knowledge, and Attitude to Screening, in a Rural Community in Ebonyi State, Nigeria. Open Journal of Ophthalmology, 6(2), 119. https://doi.org/10.4236/ojoph.2016.62017

Prabhu, M., Patil, S. H., \& Kangokar, P. C. R. (2013). Glaucoma awareness and knowledge in a tertiary care hospital in a tier-2 city in South India. Journal of the Scientific Society, 40, 3-8. https://doi.org/10.4103/0974-5009.109674

Rabiu, M. M., Al Bdour, M. D., Abu, A. M., \& Jadoon, M. Z. (2014). Prevalence of blindness and diabetic retinopathy in northern Jordan. European journal of ophthalmology, 25(4), 320-327. https://doi.org/10.5301/ejo.5000557

Rewri, P., \& Kakkar, M. (2014). Awareness, knowledge, and practice: a survey of glaucoma in north Indian rural residents. Indian journal of ophthalmology, 62(4). 482. https://doi.org/10.4103/0301-4738.132105

Rhee, D. J., Porter, R., \& Glaucoma, S. (2013). The Merck Manual Home Health Handbook (pp. 12). https://doi.org/10.1108/RR-06-2015-0144

Sathyamangalam, R. V., Paul, P. G., George, R., Baskaran, M., Hemamalini, A., Madan, R. V., \& Lingam, V., (2009). Determinants of glaucoma awareness and knowledge in urban Chennai. Indian Journal of Ophthalmology, 57, 355-360. https://doi.org/10.4103/0301-4738.55073

Saw, S. M., Gazzard, G., Friedman, D., Foster, P. J., Devereux, J. G., Wong, M. L, \& Seah, S. (2003). Awareness of glaucoma and health beliefs of patients suffering primary acute angle closure. British Journal of Ophthalmology, 87, 446-449. https://doi.org/10.1136/bjo.87.4.446

Tenkir, A., Solomon, B., \& Deribew, A. (2010). Glaucoma awareness among people attending ophthalmic outreach services in Southwestern Ethiopia. BMC Ophthalmology, 10, 17. https://doi.org/10.1186/1471-2415-10-17

Tielsch, J. M., Sommer, A., Katz, J., Royall, R. M., Quigley, H. A., \& Javitt, J. (1991). Racial variations in the prevalence of primary open angle glaucoma - The Baltimore Eye Survey. The Journal of the American Medical Association, 266, 369-374. https://doi.org/10.1001/jama.266.3.369

World Health Organization. (2016). Eye care service assessment tool.

Young, S. M., Aquino, M. C., Shabana, N., Zheng, C., Loon, S. C., See, J. L., ... Chew, P. T. (2015). Ultrasound biomicroscopic comparison of primary open-angle glaucoma and primary angle-closure glaucoma eyes in dark and light conditions. Asian Journal of Ophthalmology, 14(1), 5-16. 


\section{Annexure 1: Questionnaire}

1. Awareness about Glaucoma

\begin{tabular}{|l|l|l|l|l|}
\hline Age & Qualification & Gender & Address(City) & Job \\
\hline
\end{tabular}

2. Awareness about Glaucoma (even before being contacted/recruited for the study) Have you ever heard of the eye condition glaucoma?

\begin{tabular}{|l|l|l|}
\hline Yes & No & Can’t Say \\
\hline
\end{tabular}

3. Is Glaucoma treatable?

\begin{tabular}{|l|l|l|}
\hline Yes & No & Can’t Say \\
\hline
\end{tabular}

4. Does or did any family member have glaucoma?

\begin{tabular}{|l|l|l|}
\hline Yes & No & Can’t Say \\
\hline
\end{tabular}

5. Knowledge about Glaucoma. Tick the possible risk factors for Glaucoma. Diabetes.

\begin{tabular}{|c|c|c|c|c|c|c|}
\hline $\begin{array}{c}\text { Increased Intra } \\
\text { ocular } \\
\text { pressure }\end{array}$ & Obesity & $\begin{array}{c}\text { Family history of } \\
\text { glaucoma }\end{array}$ & Steroids & $\begin{array}{l}\text { Chronic } \\
\text { Smokin } \\
\mathrm{g} \text { and } \\
\text { Alcohol } \\
\text { intake }\end{array}$ & $\begin{array}{c}\text { None of } \\
\text { the } \\
\text { abo } \\
\text { ve }\end{array}$ & $\begin{array}{l}\text { Can't } \\
\text { say }\end{array}$ \\
\hline
\end{tabular}

6. What are the therapies for treating Glaucoma that are currently available? Tick the appropriate choices.

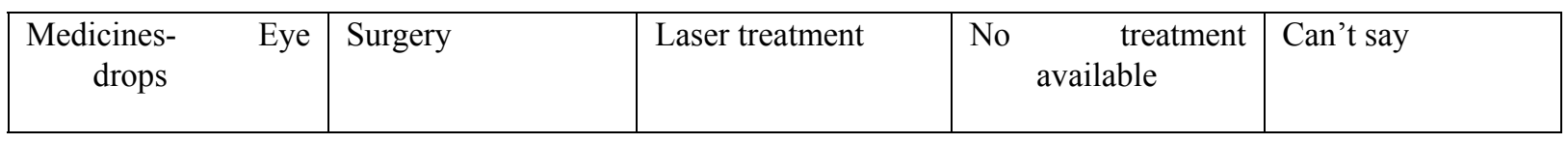

\section{Description of Glaucoma}

How would you describe it? (Record all mentioned- Symptoms)

I agree to use this information for research purposes. Signature

\section{Copyrights}

Copyright for this article is retained by the author(s), with first publication rights granted to the journal.

This is an open-access article distributed under the terms and conditions of the Creative Commons Attribution license (http://creativecommons.org/licenses/by/4.0/). 